\title{
Influence of the flight season on the health status of the carrier pigeons
}

\begin{abstract}
Carrier pigeons are highly valued for their outstanding orientation skills and high performance that they display during races. The breeding of the carrier pigeon is very important for these reasons. Increased stress and short time for regeneration during the race are an important factors that significantly affects the health of racing pigeons and their composition of bacterial microflora. The aim of this study were to observe the health status and changes in bacterial microflora of 80 racing pigeons in age $1.5-4$ years originated from holding on west of Slovakia, which for three months completed eighteen races at a distance of $120-1150 \mathrm{~km}$. At the beginning and at the end of the race season were taken the samples of swabs from cloaca and oropharynx. Comparing the most common diseases of pigeons, were found an increased incidence of coccidiosis $(52.2 \%)$, trichomoniasis $(31.9 \%)$, and respiratory syndrome $(7.2 \%)$ after the race season. The enterococcal and streptococcal intestinal flora of pigeons during the race season was dominated and composed of mainly host specific bacteria by Ent. faecalis, Ent. faecium, Ent. columbae, E. coli, Str. gallolyticus and Str. faecalis. Results are showing that also despite increased percentage of cultivation opportune pathogens, especially coagulase negative and positive staphylococci and increased prevalence of coccidiosis, trichomoniasis and respiratory syndrome, the pigeons are able to provide flight performance and cope with changes in their organism during this difficult race period.
\end{abstract}

Volume 4 Issue 2 - 2019
František Zigo,' Silvia Ondrašovičová, ${ }^{2}$

Martina Zigová, ${ }^{3}$ Ladislav Takáč, ${ }^{4}$ Jana

Takáčová

'Department of Animal husbandry, University of Pavol Jozef Šafárik in Košice, Slovakia

${ }^{2}$ Department of Physiology, University of Pavol Jozef Šafárik in Košice, Slovakia

${ }^{3}$ Department of Pharmacology, University of Pavol Jozef Šafárik in Košice, Slovakia

${ }^{4}$ Public Veterinary Medicine and Economics, University of

Veterinary Medicine and Pharmacy, Slovakia

\begin{abstract}
Correspondence: František Zigo, University of Veterinary Medicine and Pharmacy, Department of Animal husbandry, Košice, Komenského 73, 040 0I, Slovakia, Tel +42I-908-689-722,
\end{abstract} Email frantisek.zigo@uvlf.sk

Received: February 19, 2019 | Published: March 15, 2019

Keywords: racing pigeons, coccidiosis; trichomoniasis, intestinal flora, enterococci, staphylococci

\section{Introduction}

The breeding of the carrier pigeon is very important for these reasons. Nowadays, each breeder knows that it is not only targeted breeding and associated genetic predisposition of individuals but also a combination of other factors such as feeding, dietary supplements, appropriate zoohygienic conditions, prophylactic plans, adequate training load and taking into account the number of races. ${ }^{1,2}$ The most vulnerable to infections are racing and highfliers pigeons, as they perform a large number of flights in the so-called racing season. This leads to substantial exhaustion of birds and, consequently, increases their susceptibility to various diseases. ${ }^{3-5}$ The diseases that affect pigeons are divided in to contagious diseases and non contagious diseases. Viruses, bacteria, fungi and parasites are the main causes for contagious diseases while non-contagious diseases are resulted from the absence of proper nutrients as well as poisonous elements in the food. ${ }^{6}$

The main infectious illnesses of racing pigeons include: viral diseases, chlamydophilosis and parasitic diseases such as lice, mites, roundworms (Ascaridia, Capillaria), tapeworms, coccidiosis, hexamitosis, trichomonads and trematodes. The bacteria Salmonella typhimurium, Escherichia coli, streptococci, coagulase-positive (CPS) and negative staphylococci (CNS) and parasitic organisms Eimeria columbanum or Eimeria labbeanna and Trichomonas gallinae are the most common causes of clinically symptoms in stressed pigeons, which leads to reduced power in the bird and increases its number of losses. ${ }^{7,8}$

One of the most common parasitic diseases is coccidiosis. This parasitic protozoon organism affects the bird's intestines. Two types of coccidia affect pigeons: Eimeria columbarum and Eimeria labbeanna. The clinical disease due to these organisms is identical. Coccidia in the intestines produce 'oocysts', which are passed out in the faeces These mature in the environment and will then affect other birds if ingested (Figure 1).

Most adult birds carry low levels of these parasites. Only when large numbers of parasites are present is treatment necessary. Usually raised levels of coccidial oocysts are associated with sub-optimal performance but in young birds and adults under stress an acute clinical form of the disease may be seen. The parasite affects the lining of the intestine causing diarrhoea and blood may be present. Affected birds are depressed, rapidly become emaciated and may die. ${ }^{9-11}$

The second most common cause of reduced pigeon performance is the canker (Figure 2). ${ }^{26,27}$ Canker in pigeons is caused by a parasitic organism called Trichomonas columbae and three forms are recognized that affect the pharynx (throat), navel and internal organs respectively. The majority of adult pigeons are symptomless carriers of the organism but clinical cases may occur if the bird is under stress and in young pigeons the disease may be severe and even fatal. The disease is spread from adults to squabs in the crop milk and between pigeons by the oral route. ${ }^{7,10}$

Additionally, birds may contract combined infections, known as "ornithosis complex", "ornithose," "ornithosis complex," "coryza," and "one-eye colds." This group disease can be caused by infection with Chlamydia psittaci, Pasteurella spp., or mycoplasma organisms. Other gram-negative bacteria E. coli, Yersinia spp., Enterobacter spp., and viral agents such as herpesvirus may also play a role. Ornithosis complex in pigeons is a number of disorders that is need to differentiate into three separate parts. Part one is the upper respiratory such as eyes, nose, throat and sinuses (Figure 3 ). ${ }^{28}$ 


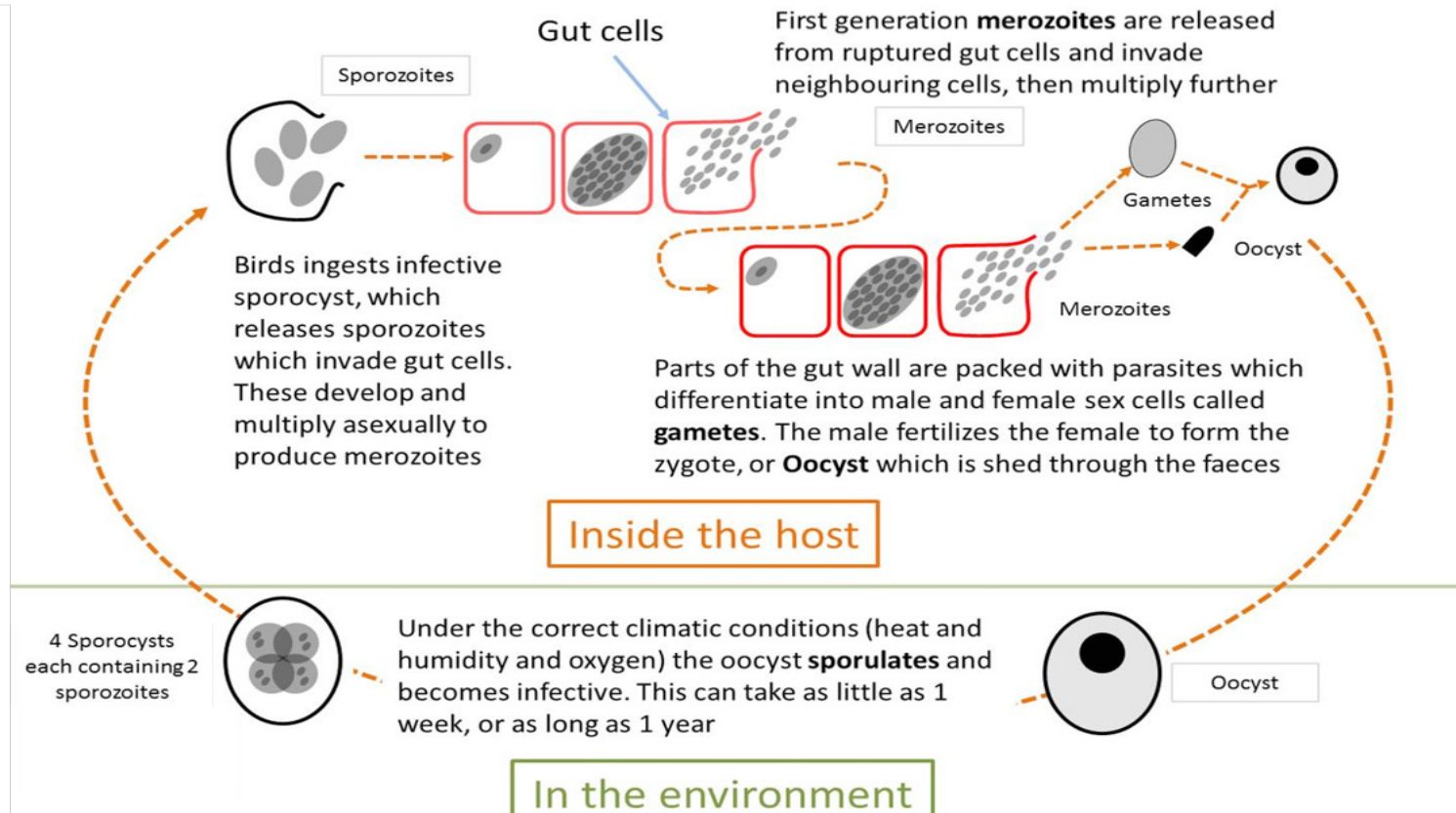

Figure I Coccidiosis life cycle in birds.
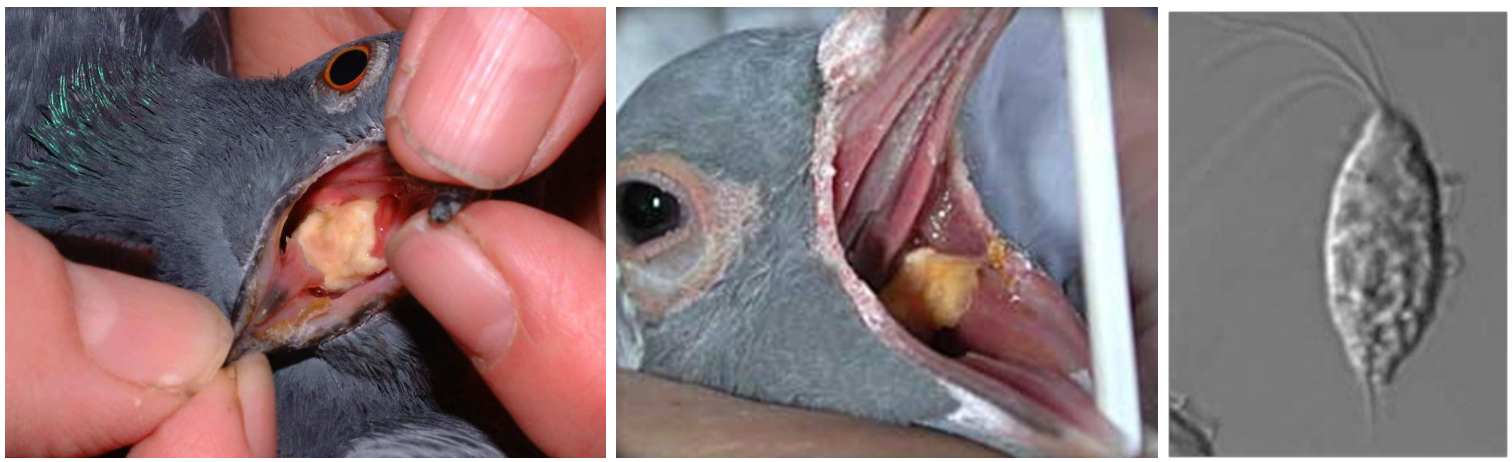

Figure 2 Canker (trichomoniasis) in racing pigeons.
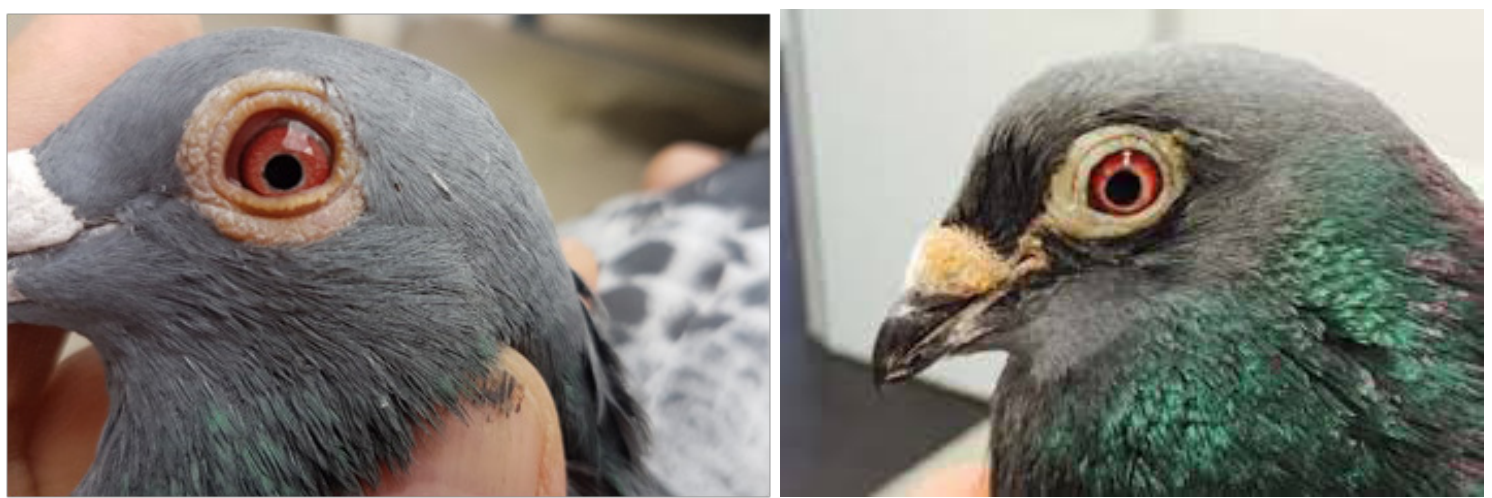

Figure 3 Ornithosis complex or coryza in racing pigeons with reduced performance.

Part two is the middle respiratory part such as trachea, syrinx (the organ that forms the sound in a bird's 'throat', however it is about 10 inches inside the body at the bifurcation of the trachea into the two main bronchi) and the bronchi. Part three is the deep respiratory trachea such as the lungs and air sacks. By far, most problems are seen in the upper respiratory part. Pigeons that have problems with their upper respiratory system can also not be motivated well. They are picked on and become demotivated in the baskets, especially after two nights of basketing. In the loft they scratch their heads, wipe theireyes over the wings, sneeze, gasp, etc etc. To put things clear, the diagnosis is as clear as day from night., 72

The aim of this study was to characterize the most common diseases and changes in bacterial microflora of carrier pigeons during the race season. 


\section{Material and methods}

\section{Animals and samples}

The study included 80 pigeons in age 1.5 - 4 years originated from holding on west of Slovakia, which for three months completed eighteen races at a distance of 120-1150 km. Clinical examination of health status was performed according to Scullion et Scullion. ${ }^{13}$ Faecal samples, swabs of the cloaca and oropharynx were collected from all 80 pigeons at the beginning of race season (may). On the end of race season (july) were taken samples of faeces and swabs from 69 pigeons because 11 pieces were lost during the races.

\section{Diagnostic and laboratory analysis}

Diagnostic of ornithosis complex was performed according to Rupipper $^{8}$ and Smith ${ }^{14}$ based on the evaluation of clinical signs such as: rhinitis, conjunctivitis, eye wiping, nasal discharge, feather loss around the eye, epiphora, sinusitis, coughing, sneezing, fluffing and poor race performance. The floatation technique was used for detecting coccidiosis and endoparasitosis from faecal samples according to Dranzoa et al., ${ }^{15}$ and Stenzel et al.. ${ }^{16}$ The coccidial oocyst count interpretation is shown in Table 1.

Table I The coccidial oocyst count interpretation from faecal samples

\begin{tabular}{ll}
\hline $\begin{array}{l}\text { Oocysts per gram } \\
\text { of faeces }\end{array}$ & Interpretation \\
\hline Less than 3,000 & Normal \\
$3,000-20,000$ & Moderate infection - performance will be affected \\
$20,000-50,000$ & Severe infection - birds may show clinical disease \\
More than 50,000 & Very severe infection \\
\hline
\end{tabular}

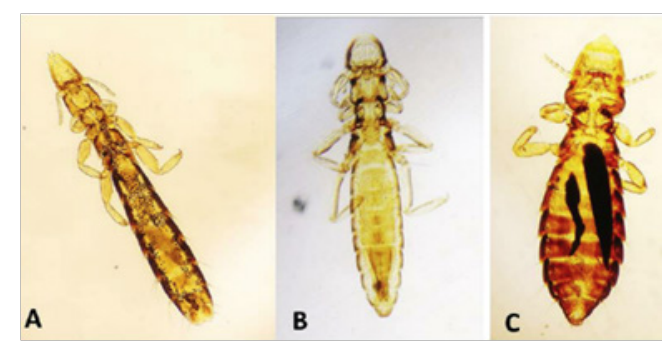

Figure 4 Avian ectoparasites: (A) Columbicola columbae, (B) Lipeurus caponis, (C) Oxylipeurus spp., (D) Menacanthus stramineus, (E) Chelopistes meleagridis, (F) Menopon gallinae. ${ }^{25}$

\section{Results and discussion}

There are many factors that influence the severity and scope of disease in racing pigeons. Healthy, well maintained birds will suffer lower morbidity and mortality immune compromised birds. Some factors that increase the pathogenicity of opportunistic diseases include: malnutrition, overpopulation (birds lower on the pecking order are more susceptible), suboptimal climate conditions within the loft, combining different age groups in the same loft, adding new pigeons to the flock, stressful situations within the flock, and racing birds that are not in proper condition. Diseases and vectors such as salmonellosis, trichomoniasis, heximitasis, mites, lice and endoparasites, can be immunosuppressive and increase morbidity and mortality of contagious diseases. According to Balicka et Pilarczyk ${ }^{10}$ and Shinde et al., ${ }^{20}$ the most common diseases pigeons include coccidiosis, trichomoniasis and respiratory infections, which is also confirmed in our study. After race season were increased $(\mathrm{P} \leq 0.05)$ incidence of trichomoniasis, coccidiosis, ectoparasitosis and respiratory syndrome (Table 2 ).
Microscopic determination of swabs from the oropharynx and crop to demonstrate the presence of trichomonads was performed according to Rupipper et al. [9] The presence of ectoparasitosis caused by Columbicola columbae, Campanulotes compar, Hohorstiella lata and Menacanthus stramineus on the skin, flight and tail feathers was performed according to Smith $^{14}$ and Hooimeijer ${ }^{17}$ (Figure 4). Each sample was cultivated on conventional nonselective media (blood agar) and selective media Endo agar, Staphylococcal medium $\mathrm{N}^{\circ} 110$, Baird-Parker agar, Edwards Medium, Mac Conkey Agar (Oxoid, (OXOID Ltd., Basingstoke, Hants, UK) according to our previous studies Zigo et al., ${ }^{4,18}$ and enterococci were identifield according to the criteria of Facklam and Collins. ${ }^{19}$ For the detection of lactobacilli were swabs of the cloaca and oropharynx put into the acidified MRS broth kept in an ice box and transported to the laboratory. The sample tubes were incubated at $37^{\circ} \mathrm{C}$ for $24 \mathrm{~h}$. Each sample was inoculated into MRS medium (BTL, Poland) supplemented with $0.05 \%(\mathrm{w} / \mathrm{v})$ Cysteine hydrochloride (Sigma-Aldrich, Poland) (MRS-cys). The plates were incubated at $37{ }^{\circ} \mathrm{C}$ for $48 \mathrm{~h}$ in $5 \% \mathrm{CO}_{2}$. Typical colonies grown on MRS medium and only catalase-negative Gram-positive rods were considered as presumtively belonging to the genus Lactobacillus. Utilization of carbohydrates by lactic acid bacteria was assayed using API kit (API 50 CHL, bioMerieux, France), and the results were analyzed using the APILAB Plus software (Ver. 3.3.3; bioMèrieux, France) (Figure 4).

\section{Statistical analysis}

Statistical analysis was performed using software Chi quadrate test for comparison of the most common diseases of pigeons and isolated strains from swabs of the cloaca and oropharynx before and after race season. Differences were considered as significant at the level of 0.05 or less.

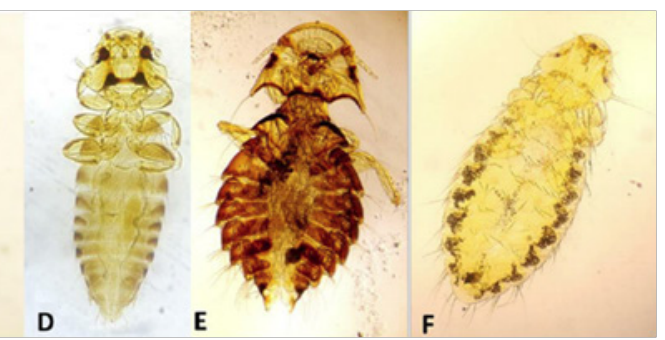

Table $\mathbf{2}$ The most common diseases of pigeons in the monitored flock during race season

\begin{tabular}{lllll}
\multirow{2}{*}{ Diseases } & \multicolumn{2}{c}{ Before race season (80) } & \multicolumn{2}{c}{ After race season (69) } \\
\cline { 2 - 5 } & $\mathrm{n}$ & $\%$ & $\mathrm{n}$ & $\%$ \\
\hline Coccidiosis & 9 & $\mathbf{1 . 3}^{\mathrm{a}}$ & 36 & $\mathbf{5 2 . 2 ^ { \mathrm { b } }}$ \\
Trichomoniasis & 6 & $\mathbf{7 . 5}^{\mathrm{a}}$ & 22 & $\mathbf{3 1 . 9}^{\mathrm{b}}$ \\
Respiratory syn $^{\mathrm{b}}$ & 0 & $\mathbf{0}^{\mathrm{a}}$ & 5 & $\mathbf{7 . 2 b}$ \\
Ectoparasitosis $^{2}$ & 0 & $\mathbf{0}^{\mathrm{a}}$ & 4 & $\mathbf{5 . 8 ^ { \mathrm { b } }}$ \\
Endoparasitosis $^{3}$ & 0 & $\mathbf{0}$ & 2 & $\mathbf{2 . 9}$
\end{tabular}

Note: $n$ - number of isolated strains from total 80 investigated pigeons before race and from 69 pigeons after race, Respiratory syn.' - respiratory syndrome determined according to clinical manifestations. Ectoparasitosis ${ }^{2}$ - caused by Columbicola columbae, Ceratophylus columbae, Endoparasitosis ${ }^{3}$ - caused by Ascaridia spp., Capillaria spp. 
Scullion $^{21}$ focused on clinical manifestations of various pigeon diseases in his work. He describes that the incidence of coccidia (Eimeria spp.) Confirmed in faecal samples does not always have a clinical course, rather the subclinical course observed in these individuals. On the contrary, the clinical manifestations of trichomoniasis increase with increasing occurrence of Trichomonas spp. isolated from oropharynx swabs. Except for trichomoniasis and coccidiosis was respiratory syndrome very common diseases in monitored flock. Respiratory syndrome is the major cause of poor performance and pigeon loss during the race season. Young birds under stress are most at risk of contracting respiratory diseases, although healthy old birds can fall ill when exposed to respiratory diseases in the race basket. Race birds with respiratory infection can be difficult to detect and yet, like a human athlete with flu, cannot compete. Clinical respiratory infection in pigeons is the end result of the interplay of a number of factors but, in particular, the type of infective organism and the vulnerability of the birds to infection are important. The classic clinical symptoms of respiratory infections include mucous in the throat, open beak and heavy breathing, rasping or gurgling while breathing, watery discharge from eyes, sometimes associated with swelling in the eye area. ${ }^{7}$

Other symptoms include discharge from the nasal area and occasionally air sac swelling or crop swelling as torn air sacs trap air under the skin. As is usually the case with pigeons, other diseases can quickly manifest themselves when birds are in distress, so other symptoms can occur, such as loose, greenish droppings and loss of weight. ${ }^{5,7,8} \mathrm{~A}$ common problems during the transport and feeding of pigeon are mixed endoparasitosis infections. ${ }^{4}$ Mixed infections with intestinal nematodes and coccidia were found in $42 \%$ of domestic pigeons and in $14.3 \%$ of the wild. As can be seen from the research, parasitic infection was greater in domestic pigeons than in the wild. ${ }^{7}$ In our study before race season we recorded low level of coccidiosis without endoparasitosis and ectoparasitosis. After the race season were increased $(\mathrm{P} \leq 0.05)$ incidence of coccidiosis and endoparasitosis. In Istanbul (Turkey), in feral pigeons nesting in famous mosques, mixed infections of coccidia and nematodes were detected: Capillaria obsignata $-19.3 \%$ and Ascaridia columbae - 14.6\%. Moreover, mixed infections were described in other regions of Turkey: E. labbeana and E. columbarum were found in wild pigeons, which were infected in $15.1 \% .^{11}$ The incidence of diseases in pigeons during the racing season may affect the presence of bacterial microflora. Microbial flora of the pigeon gastrointestinal tract is characterized by occurrence of enterococci and E. coli. Escherichia coli is usually commensal, but can also act as an opportune pathogen. Several factors are needed for $E$. coli to cause disease in pigeons, such as stress or adenoviralor herpesviral infection. ${ }^{22,23}$

In our study the enterococcal and streptococcal intestinal flora of pigeons was dominated from cloaca and oropharynx swabs The predominat gram-positive bacterial strains of both collections from swabs of cloaca are Ent. faecalis, Ent. columbae, Ent. faecium, Ent. gallinarum, and Str. faecalis (Graph 1). In an increased number $(\mathrm{P}<0.05)$ were isolated CNS (S. epidermidis, S. schleiferi, S. sciuri), CPS (S. aureus, S. gallinarum, S. intermedius), Str. faecalis, E. coli, and Ent. columbae after race season from cloaca and oropharynx swabs (Graph 1\&2).

Bergmann ${ }^{24}$ describes the problem of many breeders, which is the green faeces appearing in pigeons on arrival from races. These individuals have a green faeces despite excellent performance. Soon, their overall health deteriorates rapidly, vomiting occurs, and absorption of nutrients in the intestine is impaired. The author describes the high load of pigeons during the race due to low ambient temperatures. When performing cloacal swab it was found there was a presence of E. coli and Enterococcus spp. The bacteria Str. faecalis, Str. gallolyticus with CNS and CPS are present in the intestines of normal pigeons but can also act as an opportune pathogens for immuno depression as a result a number of stress conditions, which leads to substantial exhaustion of birds and increases their susceptibility to various diseases. ${ }^{4,18}$

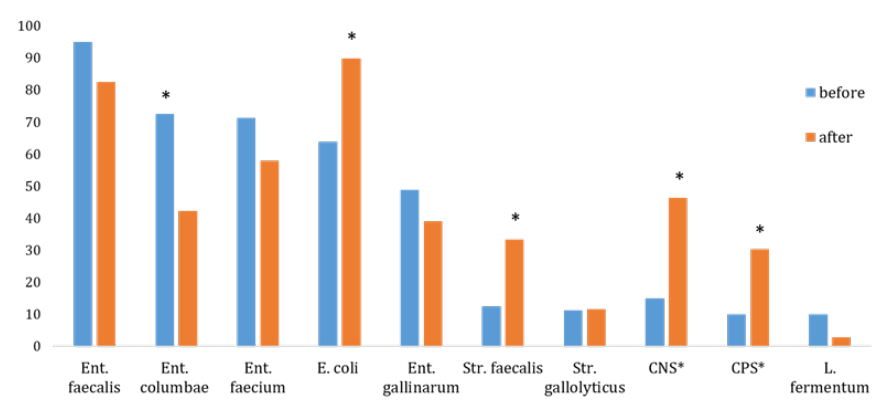

Graph I Isolated bacteria from cloaca swabs of racing pigeons.

Note: CNS $^{*}$ - coagulase negative staphylococci ${ }^{2}$ Staphylococcus epidermidis, Staphylococcus schleiferi and Staphylococcus sciuri, CPS - coagulase positive staphylococci - Staphylococcus aureus, Staphylococcus gallinarum, Staphylococcus intermedius.

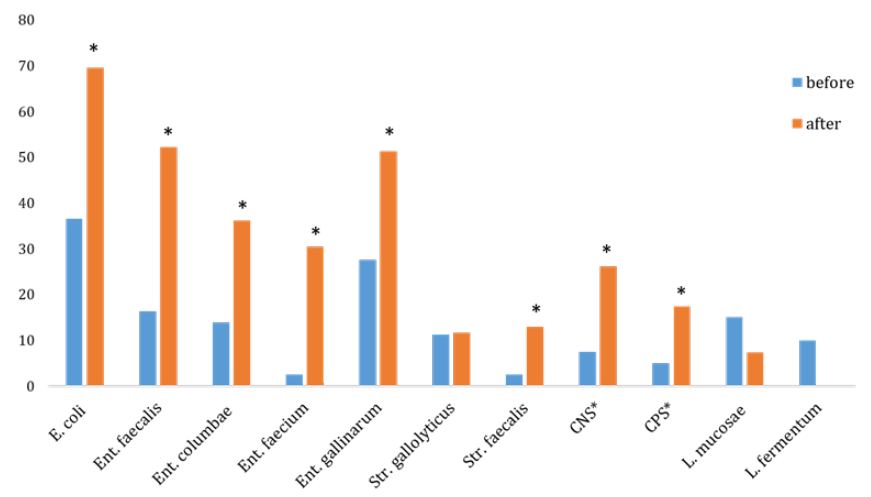

Graph 2 Isolated bacteria from oropharynx swabs of racing pigeons.

Note: $\mathrm{CNS}^{*}$ - coagulase negative staphylococci ${ }^{2}-$ Staphylococcus epidermidis, Staphylococcus schleiferi and Staphylococcus sciuri, CPS - coagulase positive staphylococci - Staphylococcus aureus, Staphylococcus gallinarum, Staphylococcus intermedius.

Serious symptoms can arise when the bacteria travels through the intestine-blood barrier. Typical is the sudden death of a pigeon which seemed completely healthy a few hours previously. This has to do with the fact that the bacteria, once in the blood, can very quickly cause serious inflammation in organs and muscles. By experimental infection of healthy pigeons whereby the Str. gallolyticus was injected directly into the blood, all the pigeons died within a few hours of being injected. Antimicrobial treatment after being infected couldn't prevent the swift death either. ${ }^{7}$

The changes of bacteria microflora and most common diseases affecting flight speed and duration racing pigeons are related to management. Lack of population control, inadequate training, improper nutrition, and marginal preventive medicine strategies remain the common denominators in poorly managed pigeon aviaries. 


\section{Conclusion}

Many factors will affect the performance of racing pigeons. Results are showing that also despite increased percentage of cultivation opportune pathogens and increased prevalence of coccidiosis, trichomoniasis and respiratory syndrome, the pigeons are able to provide flight performance and cope with changes in their organism also during this difficult race period. Maintaining sound husbandry practices and preventive medicine principles is vital to flock health Many of these diseases can be prevented with proper management. In those flocks that require veterinary assistance, intervention can provide a rapid diagnosis, effective treatment, and enhanced performance.

\section{Acknowledgments}

None.

\section{Conflicts of interest}

Author declares that there is no conflict of interest.

\section{References}

1. Zigo F, Ondrašovičová S, Takáč L, et al. Enzyme activity and biochemical parameters in racing pigeons (Columba livia domestica) during flight effort. Int J Avian \& Wildlife Biol. 2018;3(6):457-460.

2. Mohammed A. Blood biochemical profile of young and adult racing pigeons (Columba livia domestica) in Egypt. Middle East J of App Sci. 2014;4(3):528-538.

3. Zigo F, Takac L, Zigova M, et al. Effect of dietary selenium sources in racing pigeons and their effect on antioxidant markers during flying effort. Int J Avian \& Wildlife Biol. 2017;2(5):161-164.

4. Zigo F, Takáč L, Chripková M, et al. Infectious diseases of carrier pigeons and antimicrobial resistance in isolated bacteria. Int J of Sci Res. 2016;5:2277-8179.

5. Hand O. The Effects of Stress on Racing Pigeons. FHPRB. 2004.

6. Rupiper DJ. Diseases that affect race performance of homing pigeons, Part I: husbandry, diagnostic strategies, and viral diseases. J Avian Med Surg. 1998;12:70-77.

7. Rupipper DJ. Diseases that affect race performance of homing pigeons. Part II: Bacterial, fungal, and parasitic diseases. Journal of Avian Medicine and Surgery. 1998;12(3):138-148.

8. Rupiper DJ, Ehrenberg M. Practical pigeon medicine. Proc Assoc Avian Vet. 1997:479-497.

9. Rupiper JD, Briggs KT, Ehrenberg M. Management of trichomoniasis, paramyxovirus. 1994.

10. Balicka RA, Pilarczyk B. Occurrence of coccidia infection in pigeons in amateur husbandry. Diagnosis and prevention. An of Par. 2014;60:9397.

11. Koroglu E, Şimşek S. The prevalence of Eimeria species in pigeons (Columba livia) in Elazig. Fırat Universitesi Sağlık Bilimleri Dergisi Vet. 2001;15:401-403.
12. Baris S, Karatepe B, Karatepe M, et al. Parasites of domestic (Columba livia domestica) and wild (Columba livia livia) pigeons in Niğde, Turkey. Bul of the Vet Ins in Pulawy. 2008;52:551-554.

13. Scullion FT, Scullion MG. Investigation of diseases in young racing pigeons. 1997:73-75.

14. Smith SA. Parasites of birds of prey: their diagnosis and treatment. Semin Avian Exotic Pet Med. 1996;5(2):97-105.

15. Dranzoa C, Ocaido M, Katete P. The ecto, gastro-intestinal and haemo parasites of live pigeons (Columba livia) in Kampala, Uganda. Av Pat. 1999;28:119.

16. Stenzel T, Koncicki A. Occurrence of parasitic invasions in domestitc pigeons (Columba livia domestica) in the Northern Poland. Pol J of Vet Sci. 2007;10:275-278.

17. Hooimeijer J. Rinciples of veterinary support in racing pigeons. Proc Annu Conf Assoc Avian Vet. 1993;1993:151-155.

18. Zigo F, Takáč L, Zigová M, et al. Changes in bacterial microflora in young carrier pigeons during the race season. Int J Avian \& Wildlife Biol. 2017;2(2):41-44.

19. Facklam RR, Collins MD. Identification of Enterococcus species isolated from human infections by conventional test scheme. J Clin Microbiol. 1989;27:731-734.

20. Shinde NG, Gatne M., Singh A, et al. Prevalence of parasites in pigeons (Columba livia domestica) of Mumbai. Jour of Vet Par. 2008;22:235-238.

21. Scullion FT. Phatologicfindings in racing pigeons (Columba livia domestica) with young bird sickness. J Avian Med Surg. 2007;21(1):1-7.

22. Baele M, Devriese LA, Butaye P, et al. Composition of enterococcal and streptococcal flora from pigeon intestines. Jour of Appl Mic. 2002;92:348-351.

23. Kimpe A, Decostere A, Martel A, et al. Prevalence of antimicrobial resistance among pigeon isolates of Streptococcus gallolyticus, Escherichia coli and Salmonella enterica serotype Typhimurium. Avian Pathol. 2002;31:393-397.

24. Bergmann R. Sportovní výkony u holubů. (Sporting performances at the pigeons) Letu zdar. 2013;1:22.

25. Portugaliza H, Bagot M. Different species of lice (Phthiraptera), fleas (Siphonaptera) and ticks (Ixodida) collected from livestock, poultry, reptile and companion animal in Leyte Island, Philippines. Livestock Research for Rural Development. 2015;27:151.

26. Bogdan B. Trichomonoza. Arhiva Articole. 2017;22.

27. Girard YA, Rogers KH, Gerhold R, et al. Trichomonas stableri n. sp., an agent of trichomonosis in Pacific Coast band-tailed pigeons (Patagioenas fasciata monilis). Int J Parasitol Parasites Wildl. 2013;3(1):32-40.

28. De Weerd HJM. Ornithosis complex in racing pigeons, The racing pigeon. 2012;22. 